\title{
PREDator - a new structure-based approach for cross-reactivity predictions
}

\author{
Florian Koelling \\ From 8th German Conference on Chemoinformatics: 26 CIC-Workshop \\ Goslar, Germany. 11-13 November 2012
}

Ligandcentric virtual screening techniques employ in most cases three-dimensional Gaussians in order to define a molecule's entire pharmacophoric properties (ideally of a co-crystallised ligand) [1] and have been applied successfully in many prospective and retrospective drug discovery campaign [2].

Here, the development of a new pharmacophoric binding site descriptor in the spirit of Cavbase [3] is presented: Instead of focussing on ligand features, crucial amino-acid residues within the binding site are identified and represented as a pharmacophore model. Our method aims to combine the advantages of Cavbase with the smooth nature of a Gaussian pharmacophore representation, thus enabling binding site comparisons independently of sequence homology. Gaussian models are fast to compute and show the advantage that only very few parameters have to be defined. In contrast to a recently published approach where the entire binding site is defined by a Gaussian model for structure-based cross-reactivity predictions [4], PREDator employs only a few characteristic cavity-flanking amino acids [5] which are finally encoded in order to accelerate computations.

It is shown that these models, as a conceptual representation of the binding site, can be used successfully for cross-reactivity predictions. Compared to a ligandcentric approach [5] with regard to this purpose, a structure-based approach is advantageous in terms of being less dependent on the ligand-scaffold.

Published: 22 March 2013

Correspondence: florian.koelling@tu-bs.de

Institut für Medizinische und Pharmazeutische Chemie, Technische

Universität Braunschweig, Beethovenstr. 55, 38106 Braunschweig, Germany

\section{References}

1. Leach AR, Gillet VJ, Lewis RA, Tailor R: Three-Dimensional Pharmacophore Methods in Drug Discovery. J Med Chem 2010, 53:539-558.

2. Grant J, Pickup B: A Gaussian Descriptor of Shape. J Phys Chem 1995, 99:3503-3510.

3. Schmitt S, Kuhn D, Klebe G: A New Method to Detect Related Function Among Protein Indepent of Sequence and Fold Homology. J Mol Biol 2002, 323:387-406.

4. Desaphy J, Kellenberger E, Rognan D: Comparison and Druggability Prediction of Protein-Ligand Binding Sites from PharmacophoreAnnotated Cavity Shapes. J Chem Inf Model 2012, 52(8).

5. Diwan MM, et al: Exploring Polypharmacology Using a ROCS-Based Target Fishing Approach. J Chem Inf Model 2012, 52:492-505.

\section{doi:10.1186/1758-2946-5-S1-P6}

Cite this article as: Koelling: PREDator - a new structure-based approach for cross-reactivity predictions. Journal of Cheminformatics 2013 5(Suppl 1):P6.

\section{Publish with ChemistryCentral and every scientist can read your work free of charge \\ "Open access provides opportunities to our colleagues in other parts of the globe, by allowing anyone to view the content free of charge." \\ W. Jeffery Hurst, The Hershey Company. \\ - available free of charge to the entire scientific community \\ - peer reviewed and published immediately upon acceptance \\ - cited in PubMed and archived on PubMed Central \\ - yours - you keep the copyright \\ Submit your manuscript here: \\ http://www.chemistrycentral.com/manuscript/

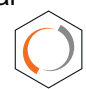 Chemistry Central}

